\title{
NUMERICAL AND EXPERIMENTAL STUDY OF \\ TURBULENT FLOW IN TWO DIMENSION \\ INCLINED WALL JET
}

\author{
A. Abdel- Fattah \\ Lecturer in Mechanical Power Engineering Department, Faculty of \\ Engineering, \\ Menoufia University, Shebin El -Kom, Egypt.
}

\begin{abstract}
In the present study, a steady, two dimension turbulent isothermal and incompressible flow of inclined wall jet has been studied numerically and experimentally. The equations of momentum, continuity and the standard $k-$ $\varepsilon$ turbulent model are solved numerically using a finite-volume method to indicate the effects of wall inclination and Reynolds number on the flow characteristics of two-dimensional inclined wall jet. The Finite volume method is formulated to suite the general grid system. The numerical results indicate the effect of different values of wall angle $\left(\theta=0^{\circ}, 5^{\circ}, 8^{\circ}, 10^{\circ}, 15^{\circ}\right.$, $30^{\circ}$ and $\left.45^{\circ}\right)$ together with various Reynolds number $\left(5 \times 10^{3}, 10 \times 10^{3}\right.$, $56 \times 10^{3}, 86.24 \times 10^{3}$ and $\left.108.732 \times 10^{3}\right)$ on the velocities $(\mathrm{u}, \mathrm{v})$, the pressure (p), the location of maximum velocity of flow $\left(b_{\max } / \mathrm{h}\right)$ and the width of reciruclation zone $\left(b_{\min } / h\right)$. The present experimental work shows the wall static pressure at different values of wall angle $\left(0^{\circ}, 5^{\circ}, 8^{\circ}\right.$ and $\left.10^{\circ}\right)$ and different values of $\operatorname{Re}\left(56 \times 10^{3}, 86.24 \times 10^{3}\right.$ and $\left.108.732 \times 10^{3}\right)$. For the range of $0^{\circ} \leq \theta \leq 45^{\circ}$, the results indicate that, when the wall angle increases, the maximum velocity decays faster and its location shifts towards free stream, while the jet spreads faster. The width of recirculation zone increases by increasing the wall angle and Reynolds number. The pressure increases by increasing the wall angle but this increment decays by increasing the Reynolds number. The numerical results give good agreement with the present experiment work and also with the experiment data of Ref. [11].
\end{abstract}

KEY WORDS: General geometry; aerofoil designs; turbo-machinery; air condition; separation flow

Manuscript received from Dr. A.Abdel - Fattah 
The mean flow characteristics in the near field of an inclined wall jet are of great practical significance engineering application as advanced aerofoil designs, film cooling of turbine blades, gas turbine combustion chamber walls, and deflectors used in air conditioning duct.

The modification of $k-\varepsilon$ turbulence model for solving the flow field of wall jet was studied by Ljuboja and Rodi [1]. Chiu and Wu [2] studied numerically the turbulent in cylinder flow during motoring utilizing a general curvilinear coordinate system. Their results showed the effect of the shapes of both cylinder head and grid distribution in cylinder air motion. Parameswaran et al. [3] studied numerically the steady and transient flows around two-dimensional bluff bodies. They indicated the surface pressure coefficient around the car. Sockol [4] examined relaxation - based multigrid solvers for the steady incompressible Navier-Stokes equation to determine their computational speed and robustness. Lopes et al.[5] studied numerically the turbulent flow and fire propagation in mountain ridges. The study of turbulent heat transfer in reciprocating engine was studied, using an algebraic grid generation technique, by Chiu and Kuo [6]. Their results showed that the turbulent wall heat flux is dependent on the shape of the cylinder head. Abdel-Fattah et al. [7] and El-Mayit et al. [8], studied the effect of single normal jet, in [7] and the effect of two symmetrical normal jets, in [8], and their locations on the recovery coefficient and recurculation zone size formed by a sudden enlargement are considered. Gargo and Gongler [9] studied the effect of spanwise pitch of shower- head holes and coolant to mainstream mass flow ratio on the adiabatic effectiveness and heat transfer coefficient on a film cooled turbine vane. Knowles [10] reported the numerical modeling of impinging jet flow using Rodi and Malin correction to $k-\varepsilon$ turbulence model carried out using the PHOENICS finite volume code. This study showed that Rodi and Molin correction tend to improve the prediction of hydrodynamic field of free and impinging jet. Loi and $\mathrm{Lu}[11]$ studied experimentally the effect of wall inclination on the mean flow in two dimensional wall jet. Their results showed the $x$ component velocity, pressure and the maximum velocity of $x$-component velocity at $\operatorname{Re}$ equals to $10^{4}$ and different wall angle $\left(0^{\circ}, 15^{\circ}, 30^{\circ}\right.$ and $45^{\circ}$ ). The interaction between dispersed particles and fluid turbulence for vertical down flow turbulent wall empedded in uniform stream studied numerically by Salo et al. [12]. Kadja et al. [13] studied a three dimensional transient numerical model for atmospheric wind flow and industry and/or traffic pollutant dispersion over terrains having a complex topography. Seyedein and Hasan [14] studied numerically coupled turbulent flow, heat transfer and macroscopic solidification in vertical twin-roll thin-strip caster. Their results showed the effect of the Darcy coefficient and the turbulent eddy viscosity-damping factor on the temperature and the velocity profiles.

In the present paper a numerical and experimental study of turbulent inclined wall jet are demonstrated to show the effects of wall inclination and Reynolds number on the velocity components $(u, v)$, the maximum $x$ - 
component velocity and its location, pressure, the location of recirculation zone.

\section{2- EXPERIMENTAL SET-UP:}

The experimental apparatus is shown schematically in Fig. (1). Compressed dry air from a storage tank was passed through the control valves and restored to a stagnation state in setting chamber, before being accelerated to a prescribed velocity value through the nozzle. The air from the nozzle was used to pass on the inclined plate. The exit height of the nozzle $\mathrm{h}$ was $15 \mathrm{~mm}$ and the width was $3 \mathrm{~mm}$ and the length of plate was $170 \mathrm{~mm}$. The stagnation pressure $\left(\mathrm{p}_{0}\right)$ was measured by a pressure gauge and the wall static pressure $(p)$ reading was taken from taps distributed along the center of the plate. The measured values of the static pressure were repeatable within $\pm 3 \%$

\section{3- GOVERNING EQUATIONS}

For a steady incompressible turbulent flow in Cartesian co- ordinates, the conservation equations for mass momentum and the equations of $k-\varepsilon$ turbulence model may be expressed in conservative form as:

Continuity equation:

$\frac{\partial \rho \mathrm{u}}{\partial \mathrm{x}}+\frac{\partial \rho \mathrm{v}}{\partial \mathrm{y}}=0$

$\mathrm{x}$-Momentum Equation:

$$
\begin{aligned}
\frac{\partial \rho u^{2}}{\partial x}+\frac{\partial u v}{\partial y}= & -\frac{\partial p}{\partial x}+\frac{\partial}{\partial x}\left[\mu_{e f f}\left(\frac{\partial u}{\partial x}+\frac{\partial u}{\partial x}\right)\right] \\
& +\frac{\partial}{\partial y}\left[\mu_{e f f}\left(\frac{\partial v}{\partial x}+\frac{\partial u}{\partial y}\right)\right]-\frac{2}{3} \frac{\partial \rho k}{\partial x}
\end{aligned}
$$

y -Momentum Equation:

$$
\begin{aligned}
\frac{\partial \rho u v}{\partial x}+\frac{\partial \rho v^{2}}{\partial y}= & -\frac{\partial p}{\partial y}+\frac{\partial}{\partial x}\left[\mu_{c f f}\left(\frac{\partial u}{\partial y}+\frac{\partial v}{\partial x}\right)+\frac{\partial}{\partial y} \mu_{e f f}\left(\frac{\partial v}{\partial y}+\frac{\partial v}{\partial y}\right)\right] \\
& -\frac{2}{3} \frac{\partial \rho k}{\partial y}
\end{aligned}
$$

Here, the effective viscosity $\mu_{\mathrm{eff}}$ is taken as the sum of the molecular and turbulent viscosities:

$\mu_{\mathrm{eff}}=\mu_{1}+\mu_{\mathrm{t}}$ 
ex us prusum wuin, uic cuuy viscosity $\mu_{t}$ is calculated with the aid of $\mathrm{k}-\varepsilon$ model of turbulence. In this model, the turbulent viscosity is determined from the turbulent kinetic energy $\mathrm{k}$ and its dissipation rate $\varepsilon$ according to:

$\mu_{\mathrm{t}}=\frac{\rho \mathrm{c}_{\mu} \mathrm{k}^{2}}{\varepsilon}$

The model is composed of two equations, one for $\mathrm{k}$ and the other for $\varepsilon$, as described below:

$$
\begin{aligned}
& \frac{\partial \rho u k}{\partial x}+\frac{\partial \rho v k}{\partial y}=\frac{\partial}{\partial x}\left(\frac{\mu_{t}}{\sigma_{k}} \frac{\partial k}{\partial x}\right)+\frac{\partial}{\partial y}\left(\frac{\mu_{t}}{\sigma_{k}} \frac{\partial k}{\partial y}\right)+G-\rho \varepsilon \\
& \frac{\partial \rho u \varepsilon}{\partial x}+\frac{\partial \rho v \varepsilon}{\partial y}=\frac{\partial}{\partial x}\left(\frac{\mu_{t}}{\sigma_{\varepsilon}} \frac{\partial \varepsilon}{\partial x}\right)+\frac{\partial}{\partial y}\left(\frac{\mu_{t}}{\sigma_{\varepsilon}} \frac{\partial \varepsilon}{\partial y}\right)+\frac{\varepsilon}{k}\left(c_{1} G-\rho \varepsilon\right)
\end{aligned}
$$

where:

$$
\begin{aligned}
& \mathrm{G}=\mu_{\mathrm{t}}\left[2\left(\frac{\partial \mathrm{u}}{\partial \mathrm{x}}\right)^{2}+2\left(\frac{\partial \mathrm{v}}{\partial \mathrm{y}}\right)^{2}+\left(\frac{\partial \mathrm{u}}{\partial \mathrm{y}}+\frac{\partial \mathrm{v}}{\partial \mathrm{x}}\right)^{2}\right] \\
& \mathrm{c}_{1}=1.44 ; \mathrm{c}_{2}=1.92 ; \mathrm{c}_{\mu}=0.09 ; \quad \sigma_{\mathrm{k}}=1 \text { and } \sigma_{\varepsilon}=1.22
\end{aligned}
$$

\section{4-TRANSFORMATION OF THE EQUATION}

The original transport equations presented above transformed from the physical domain $(x, y)$ to the computational domain $(\xi, \eta)$ through the substitution of the independent Cartesian variables by the deformed grid variables $[15,16]$, shown in Fig. (2).

In the present approach, the Cartesian components of velocity are kept as the dependent variables, since the choice of the covariant or the contravariant velocity components would lead to a much more complicated set of equations. Thus, a partial transformation is used as opposed to total transformation, which is accomplished by application of the Chain rule:

$\frac{\partial \phi}{\partial x}=\phi_{\xi} \xi_{x}+\phi_{\eta} \eta_{y}=\frac{1}{J}\left(\phi_{\xi} y_{\eta}-\phi_{\eta} y_{\xi}\right)$

and

$$
\frac{\partial \phi}{\partial y}=\phi_{\xi} \xi_{y}+\phi_{\eta} \eta_{y}=\frac{1}{J}\left(-\phi_{\xi} x_{\eta}+\phi_{\eta} x_{\xi}\right)
$$

Where $\mathbf{J}$ the Jacobian of the co- ordinate transformation is equal: 
$\mathrm{J}=\mathrm{x}_{\xi} \mathrm{y}_{\eta}-\mathrm{x}_{\eta} \mathrm{y}_{\xi}$

and;

$\xi_{\mathrm{x}}=\frac{\mathrm{y}_{\eta}}{\mathrm{J}} ; \quad \eta_{\mathrm{x}}=\frac{-\mathrm{y}_{\xi}}{\mathrm{J}} ; \quad \xi_{y}=\frac{-x_{\eta}}{j} ; \quad \eta_{\mathrm{y}}=\frac{\mathrm{x}_{\xi}}{\mathrm{J}}$

The partial differential equations describing continuity and momentum can be represented by:

Continuity equation:

$\frac{\partial \rho U}{\partial \xi}+\frac{\partial \rho \mathrm{V}}{\partial \eta}=0.0$

Momentum equations:

$$
\begin{aligned}
\frac{\partial \rho U \Phi}{\partial \xi}+\frac{\partial \rho V \Phi}{\partial \eta} & =\frac{\partial}{\partial \xi}\left[\frac{\Gamma_{\Phi}}{J}\left(\alpha \frac{\partial \Phi}{\partial \xi}+\beta \frac{\partial \Phi}{\partial \eta}\right)\right] \\
& +\frac{\partial}{\partial \eta}\left[\frac{\Gamma_{\Phi}}{J}\left(\beta \frac{\partial \Phi}{\partial \xi}+\gamma \frac{\partial \Phi}{\partial \eta}\right)\right]+S_{\Phi}(\xi, \eta) J
\end{aligned}
$$

Where $S_{\Phi}$, is a general source term. In the previous equation, the metric coefficients $\alpha, \beta$ and $\gamma$ and also contravariant velocities $U$ and $V$ are defined as:

$\alpha=x_{\eta}^{2}+y_{\eta}^{2} ; \quad \beta=x_{\xi} x_{\eta}+y_{\xi} y_{\eta} ; \quad \gamma=x_{\xi}^{2}+y_{\xi}^{2}$

and

$U=y_{\eta} u-x_{\eta} v, \quad V=x_{\xi} v-y_{\xi} u$

\section{5- NUMERICAL ALGORITHM}

A finite volume method is adapted for the location of two components of the velocity vector, which are located at the center of each face of the control volume (contravariant positions). Other scalars, such as turbulence quantities, are positioned at the geometric center of control volumes. Continuity and momentum equations are linked through pressure following the SIMPLEC procedure, in a formulation adapted to a boundary fitted co- ordinate system. For this purpose, two simplified momentum equations are written in each contravariant position of the control volume. Substitution of these equations in continuity equation yields the following pressure correction equation:

$$
A_{p} P_{p}^{\prime}=\sum A_{n b} P_{n b}^{\prime}+S^{*}+S^{* *}
$$

where: 
and;

$$
S^{* *}=\left(\frac{1}{A_{p_{u}}^{u}} \beta \frac{\partial P^{\prime}}{\partial \eta}\right)_{E}-\left(\frac{1}{A_{p}^{u}} \beta \frac{\partial P^{\prime}}{\partial \eta}\right)_{W}+\left(\frac{1}{A_{p}^{v}} \beta \frac{\partial P^{\prime}}{\partial \xi}\right)_{N}-\left(\frac{1}{A_{p}^{v}} \beta \frac{\partial P^{\prime}}{\partial \xi}\right)_{S}
$$

In the equations above $\mathrm{U}^{*}$ and $\mathrm{V}^{*}$ are the starred contravariant velocities, obtained from equation (16) after the solution of momentum equations to obtain the starred velocities $u^{*}$ and $v^{*}$. The pressure correction field obtained though the resolution of the previous equations is used to correct two velocity components in each control volume face. Using expressions like the one presented next for the west face:

$$
\begin{aligned}
& u_{w}=u_{w}^{*}+\left[\frac{1}{A_{p}^{u}}\left(J \xi_{x} \frac{\partial P^{\prime}}{\partial \xi}+J \eta_{x} \frac{\partial P^{\prime}}{\partial \eta}\right)\right]_{w} \\
& v_{w}=v_{w}^{*}+\left[\frac{1}{A_{p}^{v}}\left(J \xi_{y} \frac{\partial P^{\prime}}{\partial \xi}+J \eta_{y} \frac{\partial P^{\prime}}{\partial \eta}\right)\right]_{w}
\end{aligned}
$$

The discretized transport equations are solved using the tri-diagonal matrix algorithm (TDMA) with sweeps in the two computational directions.

\section{6- RESULTS AND DISCUSSIONS}

\section{6-1 x-Component Velocity Distribution}

A representative selection of dimensionless $x$-component velocity profiles $\left(\mathrm{u} / \mathrm{u}_{\mathrm{m}}\right)$ for different dimensionless distance $(\mathrm{x} / \mathrm{h})$ and different value of wall angle $\left(\theta=15^{\circ}\right.$ and $\left.45^{\circ}\right)$ and $\operatorname{Re}=10^{4}$ are shown in Figs. (3a) and ( $3 b$ ). From these figures it can be seen that the $\mathrm{x}$-component $\left(\mathrm{u} / \mathrm{u}_{\mathrm{m}}\right)$ decreases by increasing the distance $(\mathrm{x} / \mathrm{h})$ for all different wall angle. As wall angle increases the separation point occurs earlier at the upper stream. For $45^{\circ}$ wall angle the separation starts at the beginning. This is due to the centrifugal force increases in the down stream direction. Also, the comparison between the numerical results and the experimental data of Ref. [11], are shown in these figures. The dimensionless of maximum $x$ component velocities of jet $\left(u_{\max } / u_{m}\right)$ versus the distance $(x / h)$ are shown in Figs (4 and 5). From Fig. (4), it can be seen that, the maximum velocity decreases along distance $(\mathrm{x} / \mathrm{h})$. This is because the flow area is increased in the down stream direction. Also the velocity is decreased by increasing the wall angle, this is because the increment of area of flow increases as the wall angle increases. The effect of the Reynolds number on the dimensionless of maximum $x$-component velocities of jet $\left(u_{\max } / u_{m}\right)$ is shown in Fig. (5). It is noticed that the maximum velocity increases by increasing 
the Reynolds number, but the increment of this velocity decays at higher Re. This is due to the increase of inertia force by increasing the Reynolds number. The effects of wall angle and the Reynolds number on the $x$ component velocity profiles are shown in Figs (6 and 7). From Fig. (6) it can be seen that the velocity value decreases by increasing of wall angle and the peak of this velocity moves towards free stream. This is due to the area of secondary flow, which occurs in the main flow increases by increasing the wall angle. Also this velocity increases by increasing the Reynolds number but at higher values of $\mathrm{Re}$, the trends of this velocity are similar, see Fig. (7). This is because the initial flow velocity was considered as the mean value of main velocity. The variation of dimensionless position of maximum velocity of jet flow $\left(b_{\max } / \mathrm{h}\right)$ along dawn stream direction for different values of wall angle and Reynolds number are illustrated in Fig (8 and 9). From these figures it can be seen that the location of this velocity shifts towards free stream along the down stream direction at any values of wall angle and $\mathrm{Re}$. The change of the location of the maximum velocity increases by increasing the wall angle at constant values of $x / h$ and $R e$, see Fig. (8). This is because the jet spreads faster by increase the wall angle. But these locations of the max. velocity are not quite clear by increasing the Reynolds number. This is because the changes of spreading jet are small by increase the Reynolds number, see Fig. (9). The influence of wall angle and Reynolds number on the width of recirculation $z$ one $\left(b_{\min } / h\right)$ is shown in Figs. (10 and 11). The width of recirculation zone increases along down stream direction for all values of $\theta$, and Re. This width is increased by increasing the wall angle at constant value of $R e$ and $x / h$, see Fig. (10). This is because the centrifugal force, which occurs in flow, increases by increasing the wall angle. From Fig. (11), it is noticed that this width of recirculation zone increases as $\mathrm{Re}$ increases.

\section{2 .y- Component velocity distribution}

The y-component velocity distributions $\left(\mathrm{v} / \mathrm{u}_{\mathrm{m}}\right)$ at different distance $(\mathrm{x} / \mathrm{h})$ are shown in Fig. (12). From this figure, it can be seen that, at constant $\operatorname{Re}$ and wall angle $\left(\operatorname{Re}=10000\right.$ and $\left.\theta=15^{\circ}\right)$ the velocity which occurs in the flow at $\mathrm{x} / \mathrm{h}=1$ has a peak positive value and decreases in the down stream direction. This decay of velocity is small at higher values of distance $(x / h)$. This velocity changes from positive value to negative value in down stream direction. The profiles of velocity has two minimum values, one near the wall, this is due to recirculation zone and the other in the mean flow jet. This is because the distribution of this velocity is affected by $\mathrm{x}$-component velocity distribution, Figs (13 and 14) show the effect of wall angle and the Reynolds number on the $y$-component velocity profile at $x / h=7$. From Fig. (13) it can be seen that the absolute of peak value increases by increasing the wall angle. The effect of the Reynolds number on the $y$-component velocity at constant values of $\left(\theta=15^{\circ}\right.$ and $\left.x / h=7\right)$ is shown in Fig.(14). From this figure, it can be seen that the value of this velocity increases by increasing the Reynolds number. This is due to the fact that, this velocity depends on the mean velocity that increases by increasing Reynolds number. 
The results of dimensionless pressure distribution $\left(\mathrm{p} /\left(0.5 \mathrm{p} u_{m}^{2}\right)\right.$ at different values of wall angle are shown in Figs. (15a, 15b,15c and 15d), each for different values of Re. From these figures at any value of Re, It is noticed that, the value of static pressure decreases in down stream direction until minimum value and then increases along the wall surface at $0^{\circ}$ and $5^{\circ}$ wall angle. But the trend of this pressure from the beginning increases in down stream direction at other value of tested wall angle, see Figs (15b,15c and $15 \mathrm{~d}$ ) .This is because for case of $0^{\circ}$ and $5^{\circ}$ wall angle, the effect of viscous force is larger compared with the effect of centrifugal force, but at other value of wall angle the effect of centrifugal forcs ircreases more than the effect of viscous force.

Figures (16a, 16b, 16c, and 16d), each for different value of wall angle $(\theta)$, show the results of dimensionless pressure distribution $\left(\mathrm{p} /\left(0.5 \rho u_{m}^{2}\right)\right.$ along the down stream direction at different values of Reynolds number. From these figures at any value of wall angle, it can be seen that static pressure increases as the Reynolds number increases. This is because the inertia force are larger than the viscous force for the case of increasing the Re. This increment is less for the case of increasing the wall angle, see Figs (16c and 16d). The comparison between the numerical and present experimental work gives fair agreement.

\section{CONCOLUSIONS}

The behavior of fluid flow from turbulent jet on the inclined wall with different distance of $\mathrm{x}$-direction and with different values of wall angle and Reynolds number were studied numerically and experimentally. The major conclusions of this research could be summarized as follows:

1- The $\mathrm{x}$ - component of velocity decreases by increasing the wall angle at constant $R e$ and increases with $R e$ at constant wall angle.

2- The max. value of $x$-component velocity ( main flow velocity) decreases by increasing the wall angle and $\mathrm{Re}$, but the increment of this velocity decays for higher value of $R e$.

3- The location of maximum value of main flow shifts towards free stream in down stream direction also by increasing the wall angle at different values of $\operatorname{Re}$.

4- The point of separation was found to depend on wall angle, it moves back in the upstream flow direction by increasing the wall angle and Re.

5- The width of recirculation zone increases in down stream direction by increasing the values of wall angles.

6- The static pressure on the wall surface increases by increasing the wall angle. This pressure also increase by increasing the Reynolds number but the increment is less at higher Re.

7- The comparison between the numerical results and experimental measuring gives fair agreement. 


\section{REFERNCES}

[1] Ljuboja, M. and Rodi, W., "Calculation of Turbulent Wall Jets with an Algebraic Reynolds Stress Model", Journal of Fluid Engineering, Vol.102, pp.350-356, 1980.

[2] Chiu, C. P. and Wu, T. S., "Numerical Study of Turbulent in Cylinder Flow During Motoring Utilizing a General Curvilinear Coordinate System", Int. J. Heat and Fluid Flow, Vol.11, no.4, Pp.303-310, 1990.

[3] Parameswaran S., Srinivasan, A. and Sun, R., "Numerical Aerodynamic Simulation of Steady and Transient Flows Around Two-Dimensional Bluff Bodies Using the Nonstaggered Grid system", Numerical Heat Transfer, Part A, Vol. 21, pp.443-461, 1992.

[4] Sockol, p.M., "Muligrid Solution of The Navier- Stokes Equations on Highly Stretched Grids", Int. J. Numerical Methods Fluids, Vol. 17, pp.543-566, 1993.

[5] Lopes, A.M.G., Sousa, A.C.M. and Viegas, D.X., "Numerical Simulation of Turbulent Flow and Fire Propagation in Complex Topography", Numerical Heat Transfer, Part A, Vol.27, pp. 229-253, 1995.

[6] Chiu, C.P. and Kuo, Y.S., "Study of Turbulent Heat Transfer In Reciprocating Engine Using an Algebraic Grid Generation Technique", Numerical Heat Transfer, Part A, Vol. 27, pp.255-271, 1995.

[7] Abdel Fattah, A., El Mayit M .M. and Dyab, A.R., "Variation of Corner Recirculation Zone in Sudden Enlargement Square Duct with Normal Single Jet", Proceeding of Fifth International Conference of Fluid Mechanics, Cairo, pp. 1359- 1369, 1995.

[8] El Mayit M .M., Dyab, A.R. and Abdel Fattah, A., "An Experimental Study of the Pressure Recovery Coefficient in Sudden Enlargement Square Duct Affected with Two Normal Jets", Proceeding of Fifth International Conference of Fluid Mechanics, Cairo, pp. 749- 761, 1995.

[9] Gargo V.K. and Gaugler, R.E., "Leading Edge Film-Cooling Effects on Turbine Blade Heat Transfer", Numerical Heat Transfer, Part A, Vol. 30, pp.165-186, 1996.

[10] Knowles, K., "Computational Studies of Impinging Jets Using k- $\varepsilon$ Turbulence Models", Int. J. Numerical Methods Fluids, vol.22, pp.799$810,1996$.

[11] Loi, J.C.S. and Lu, D., "Effect of Wall Inclination on the Mean Flow and Turbulence Characteristics in a Two Dimensional Wall Jet", Int. J. Heat and Fluid Flow, Vol. 17, pp. 377-385, 1996.

[12] Sato, Y., Hishida. K. and Maeda M., "Effect of Dispersed Phase on Modification of Turbulent Flow in Wall Jet", Journal of Fluids Engineering vol.118, pp.307 314, 1996.

[13] Kadjia M., Anagnostopoulos, J.S. and Bergeles "Study of Wind Flow and Pollutant Dispersion by Newly Developed Precision- Improving Methods", Int. Comm. Heat Mass Transfer Vol. 23, no.8, pp. 10651076. 1996. 
Turbulent Flow, Heat Transfer, and Macroscopigativin ur coupied Vertical Twin Roll Thin-Strip Caster", Numerical Heat Transfer, Part Vertical Twin_Roll Thin-Strip Caster", Numerical Heat Transfer, Part A, Vol. 32, pp. $221-246,1997$.

[15] Snderson, J.D, Degrez, G., Dick, E. and Grundmann, R., "Computational Fluid Dynamics", A Van Karman Institute Book, 1992.

[16] Hoffman J.D., "Numerical Methods for Engineers and Scientists", McGraw-Hill, Inc. New York, 1992.

\section{NOMENCLATURE}

$\begin{array}{ll}b_{\max } & \text { Position of maximum velocity of flow } \\ b_{\min } & \text { Width of separation zone } \\ \mathrm{J} & \text { Jacobian of transformation } \\ \mathrm{P} & \text { Pressure } \\ \mathrm{P}_{\mathrm{o}} & \text { Stagnation pressure } \\ \mathrm{p}^{*} & \text { Pressure correction } \\ \mathrm{R}_{\mathrm{e}} & \text { Reynolds number }\left(\rho \times \mathrm{u}_{\mathrm{m}} \times \mathrm{h}\right) / \mu \\ \mathrm{S} \Phi & \text { Source term } \\ \mathrm{S}^{*}, \mathrm{~S}^{* *} & \text { Source term in p equation } \\ \mathrm{u}, \mathrm{v} & \text { Cartesian velocity components } \\ \mathrm{u}_{\mathrm{m}} & \text { Averaged nozzle exit velocity } \\ \mathrm{u}_{\max } & \text { Max. velocity of main flow } \\ \mathrm{u}^{*}, \mathrm{v}^{*} & \text { Starred velocities } \\ \mathrm{U}, \mathrm{V} & \text { Contravariant velocity } \\ \mathrm{U}^{*}, \mathrm{~V}^{*} & \text { Starred contravariant velocities } \\ \mathrm{x}, \mathrm{y} & \text { Axis Cartesian co- ordinate system } \\ \alpha, \beta, \gamma & \text { Contravariant metric relations } \\ \Gamma \Phi & \text { Diffusion coefficient } \\ \mu & \text { Dynamic viscosity } \\ \xi, \eta & \text { Transformed Coordinates } \\ \rho & \text { Density } \\ \phi & \text { General variable }\end{array}$




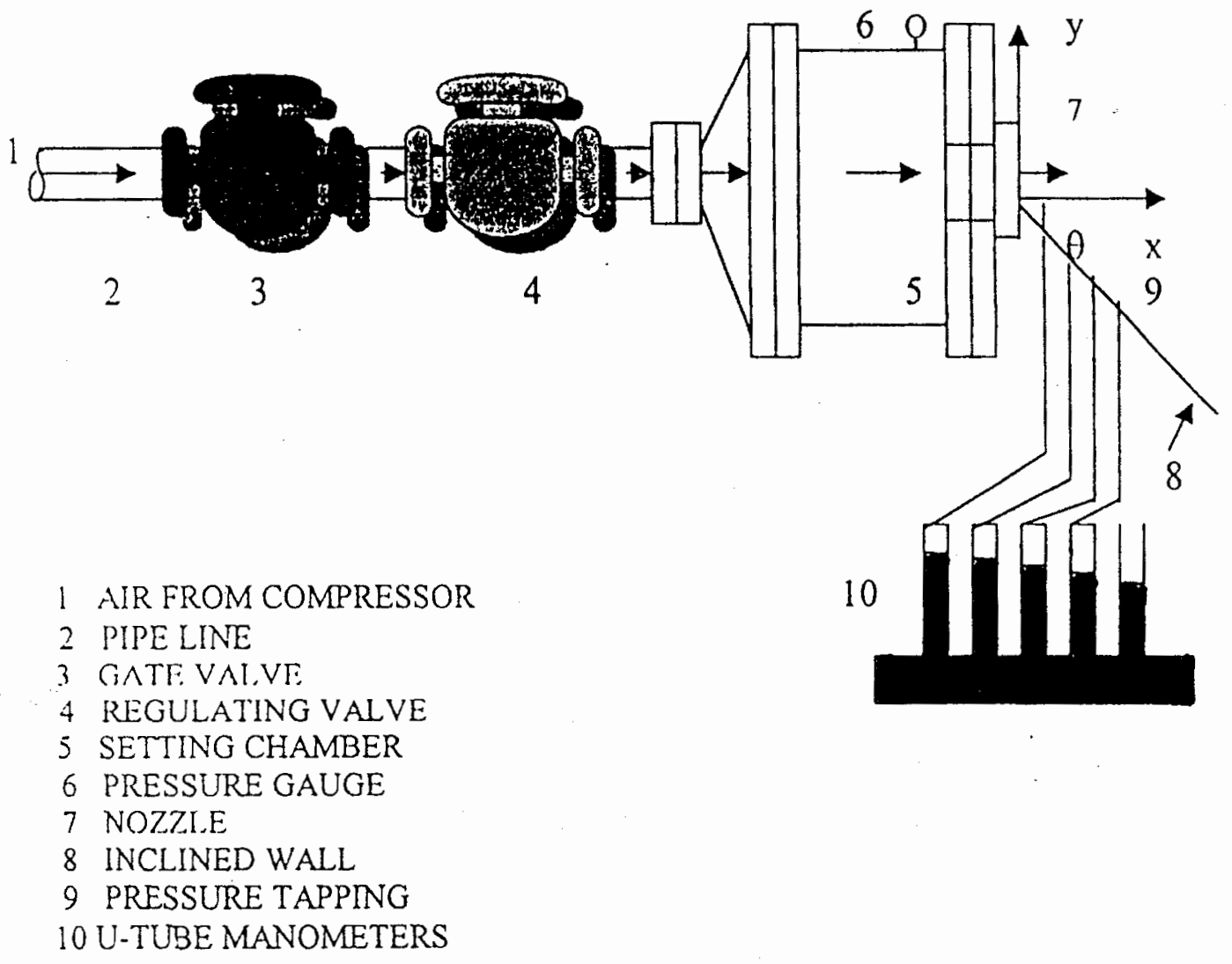

Fig. (1) Schematic diagram of experimental apparatus

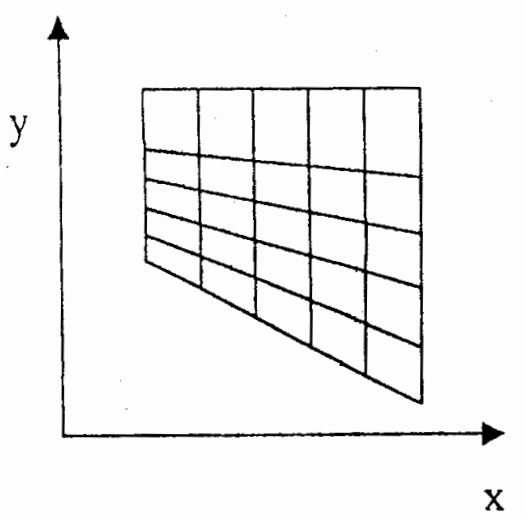

Fig.

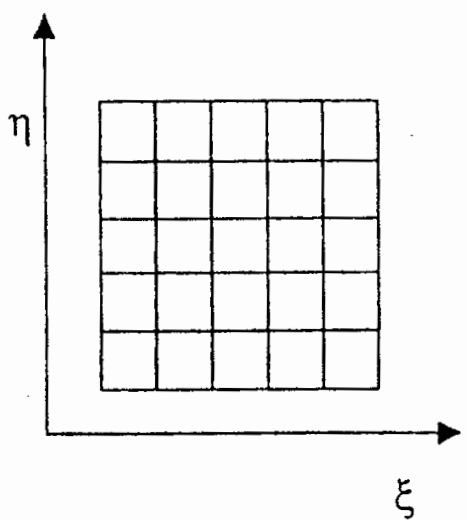

(b) Computational

(a) Physical

Fig. (2) Physical and Computational domain 


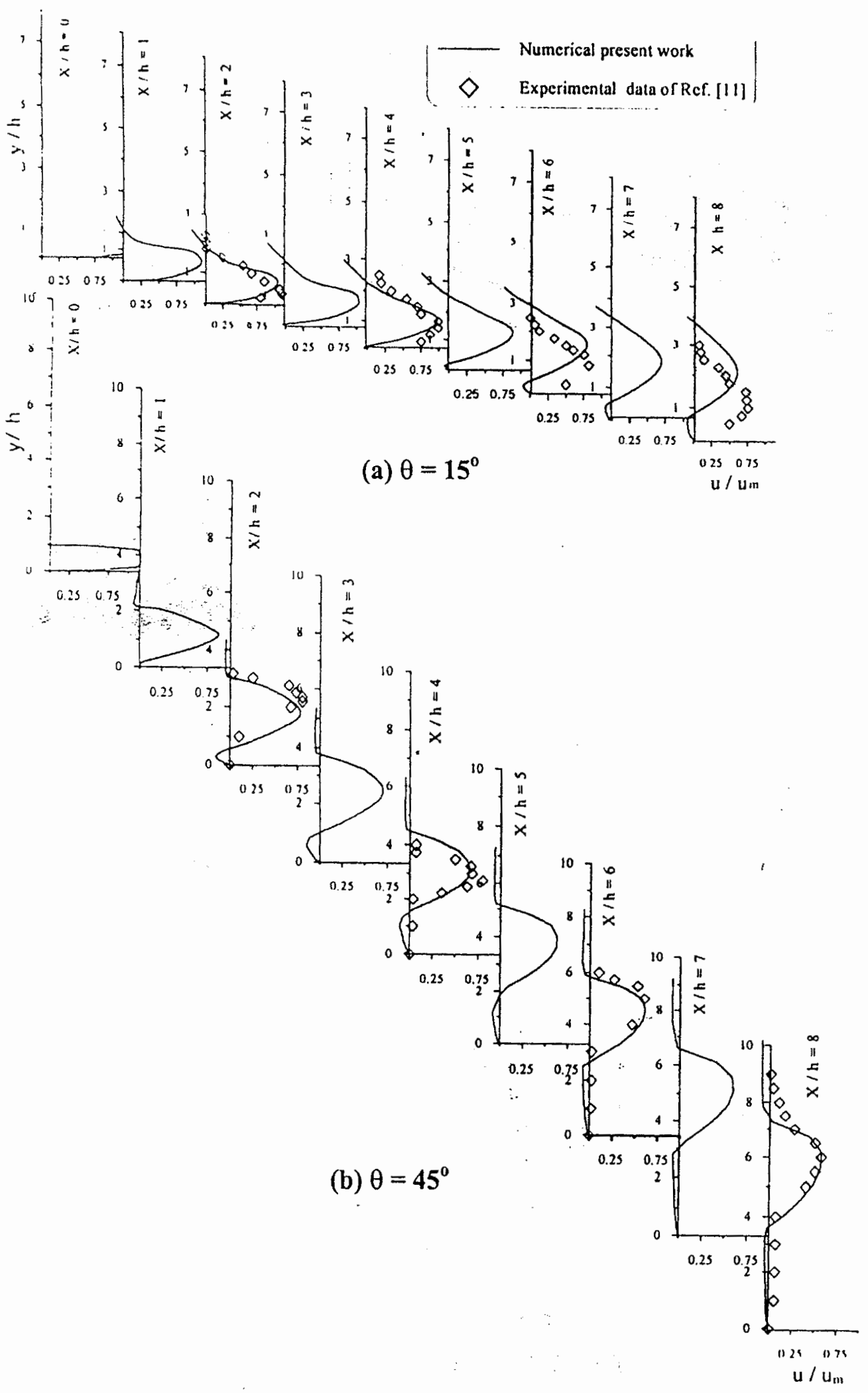

Fig. (3) Dimensionless $x$-component velocity distribution at $R \mathbf{e}=\mathbf{1 0 0 0 0}$ 


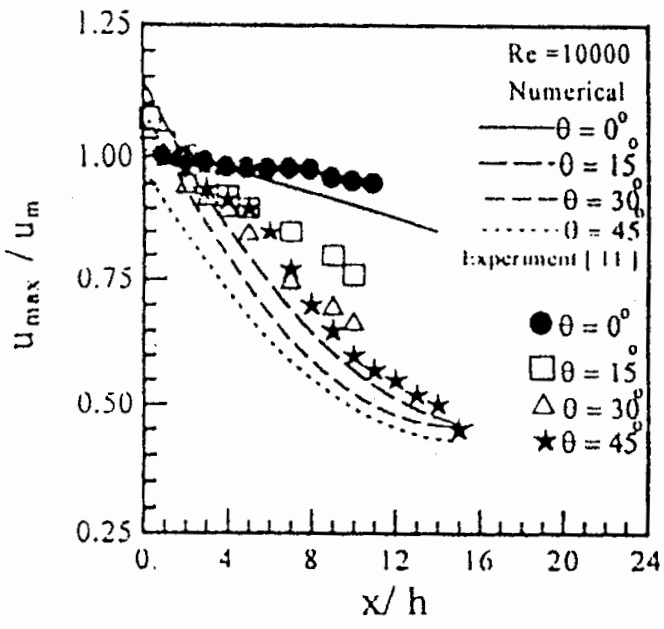

Fig. (4) Max. $x$-component velocity $\left(u_{\max } / u_{m}\right)$ at $x / h=7$ for various $\theta$

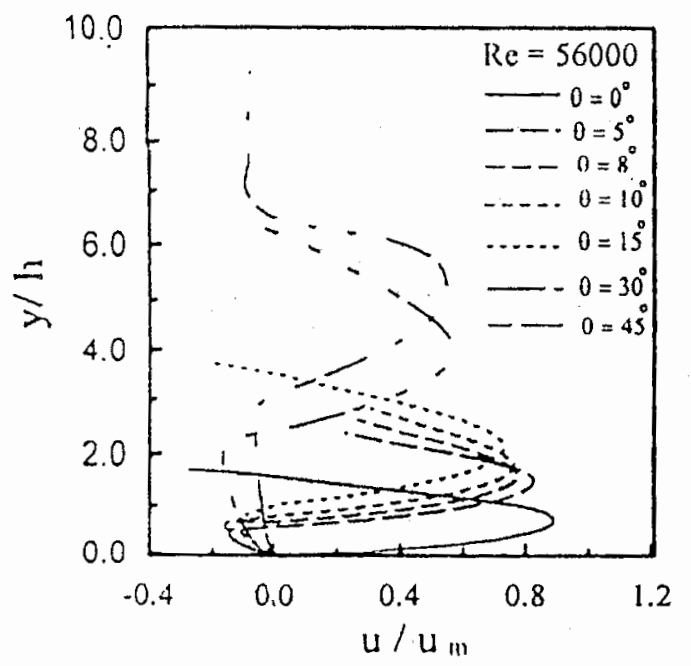

Fig. (6) Distribution of velocity $\left(u / u_{m}\right)$ at $x / h=7$ for various $\theta$

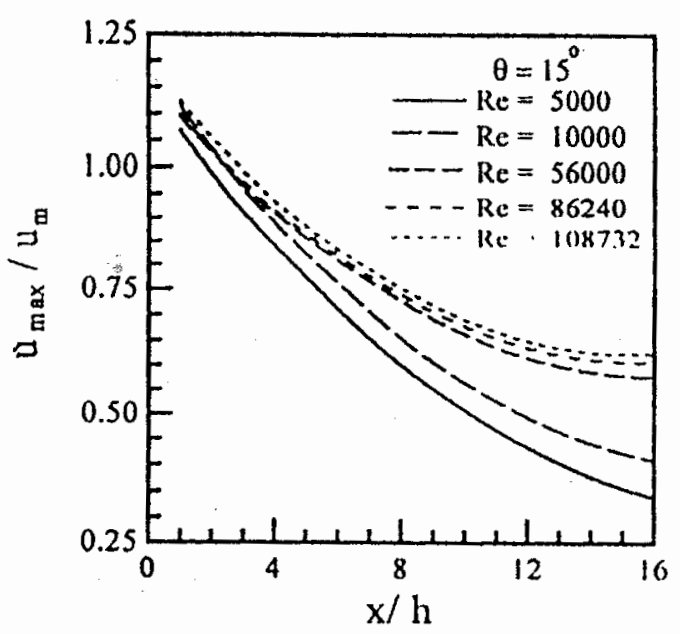

Fig. (5) Max. x-component velocity $\left(u_{\max } / u_{m}\right)$ at $x / h=7$ for various $\mathrm{Re}$

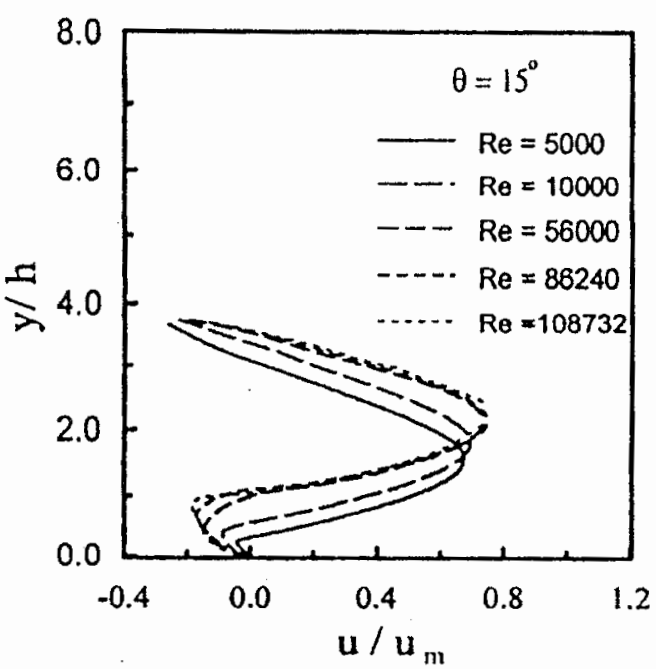

Fig. (7) Distribution of velocity $\left(\mathrm{u} / \mathbf{u}_{\mathrm{m}}\right)$ at $\mathrm{x} / \mathrm{h}=7$ for various $\mathrm{Re}$ 


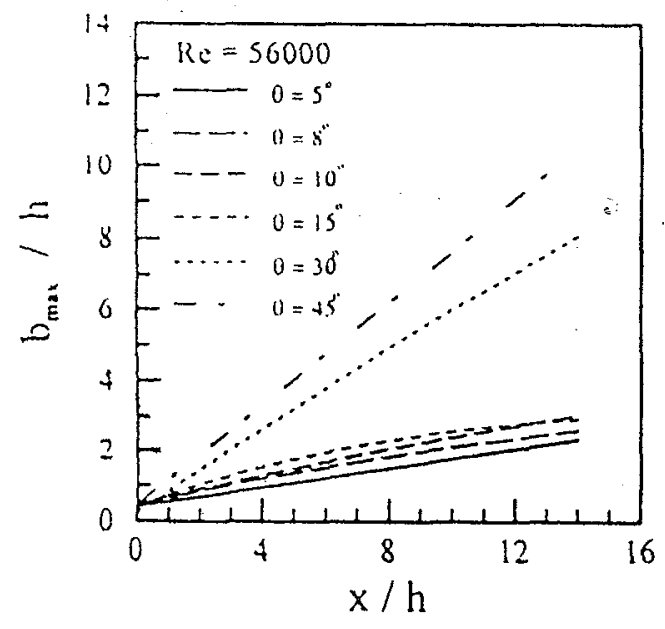

Fig. (8) Variation of position of Max. $\mathrm{x}$-component velocity for various $\theta$

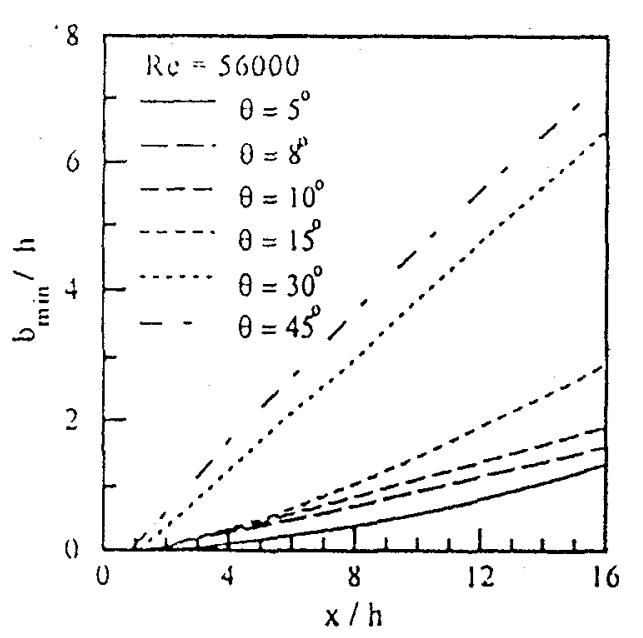

Fig. (10) Variation of width of recirculation zone for various $\theta$

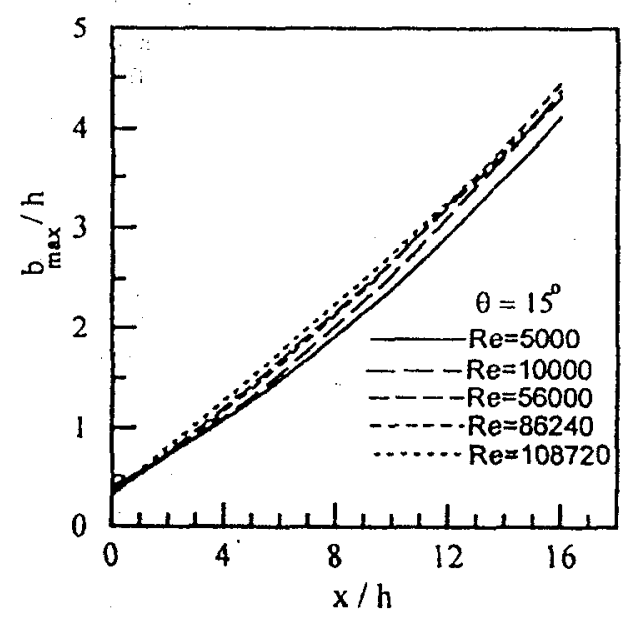

Fig. (9) Variation of position of Max. $x$-component velocity for various $\mathrm{Re}$

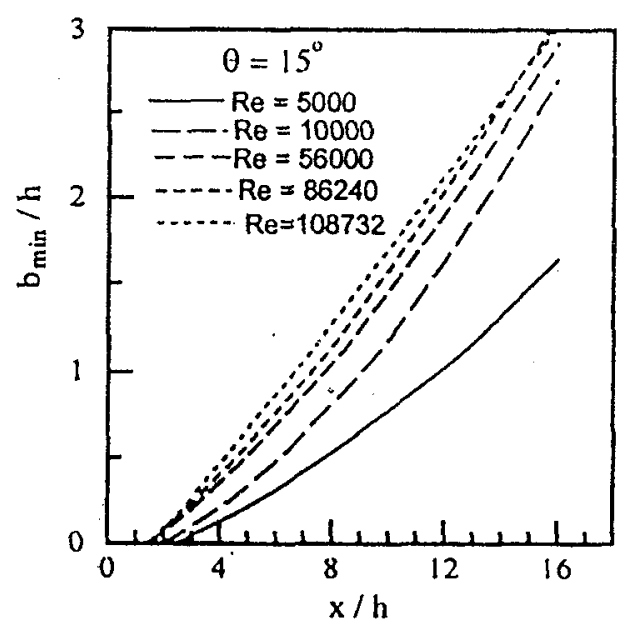

Fig. (11) Variation of width of recirculation zone for various $R e$ 


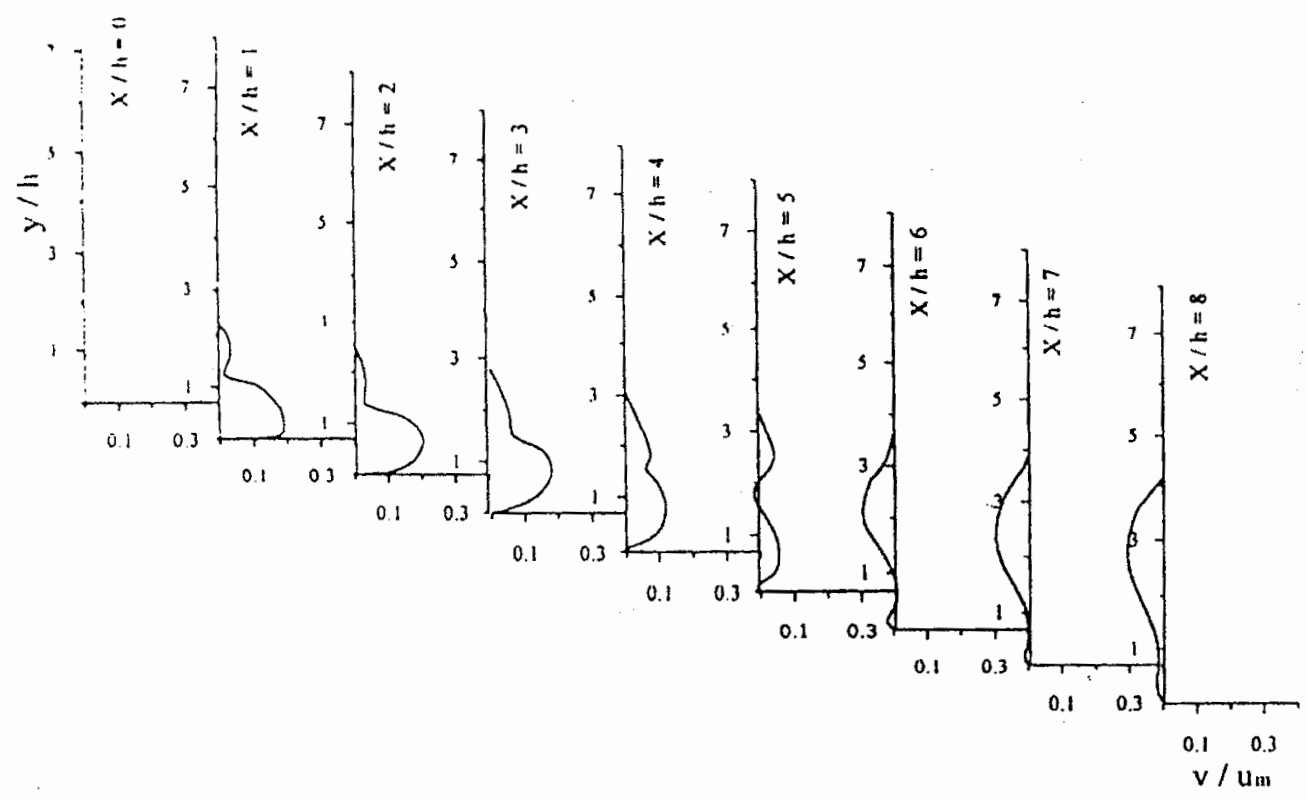

Fig. (12) Dimensionless y-component velocity distribution for $\left(\theta=15^{\circ}, \operatorname{Re}=10000\right)$

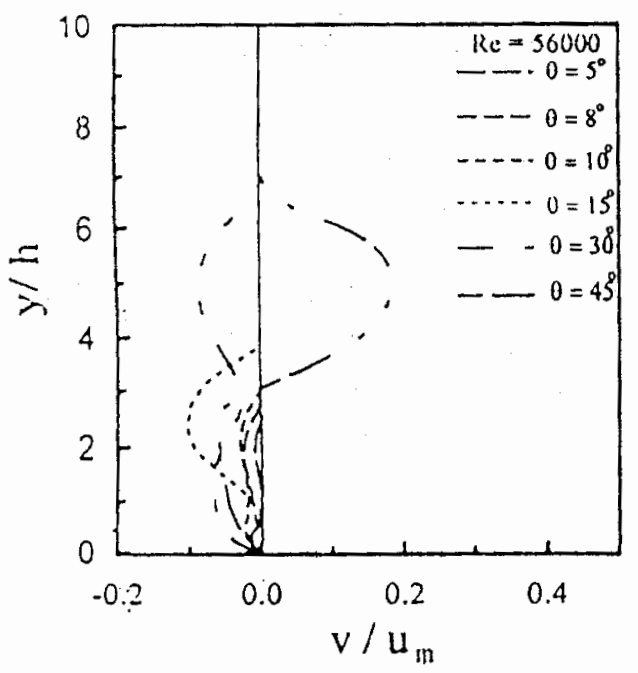

Fig. (13) Distribution of velocity $\left(\mathrm{v} / \mathrm{u}_{\mathrm{m}}\right)$ at $\mathrm{x} / \mathrm{h}=7$ for various $\theta$

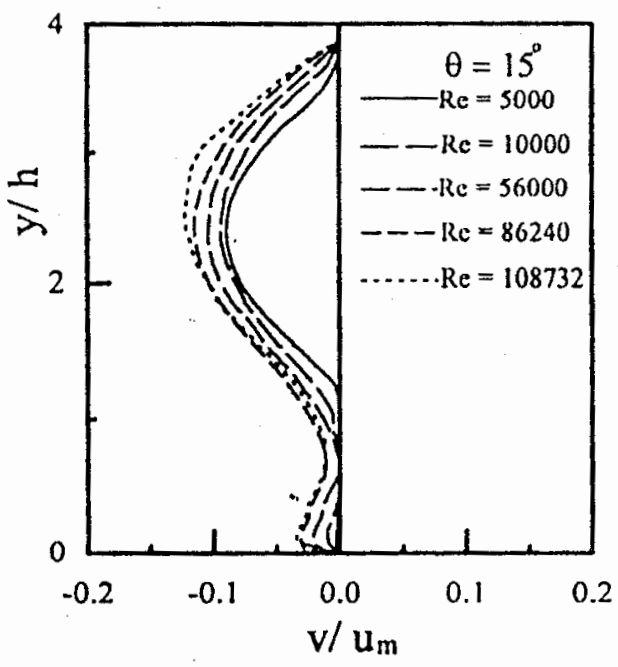

Fig. (14) Distribution of velocity $\left(v / u_{m}\right)$ at $x / h=7$ for various $R e$ 


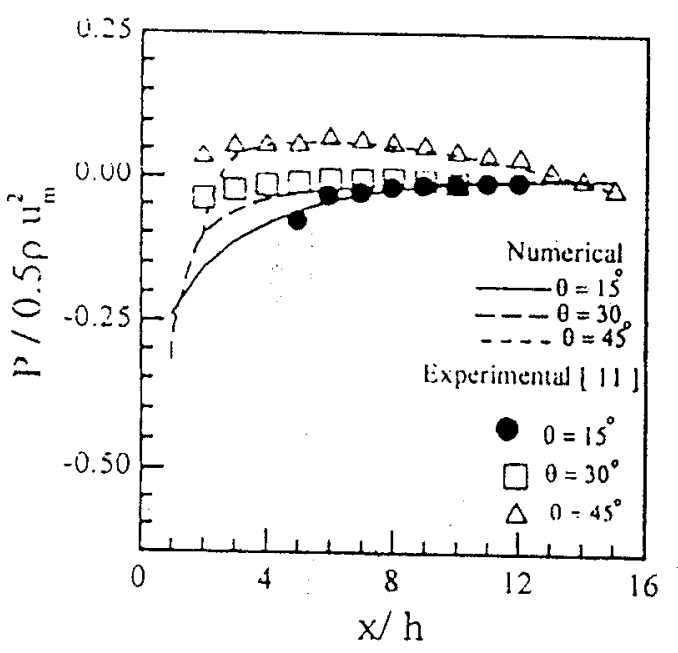

(a) $\operatorname{Re}=10000$

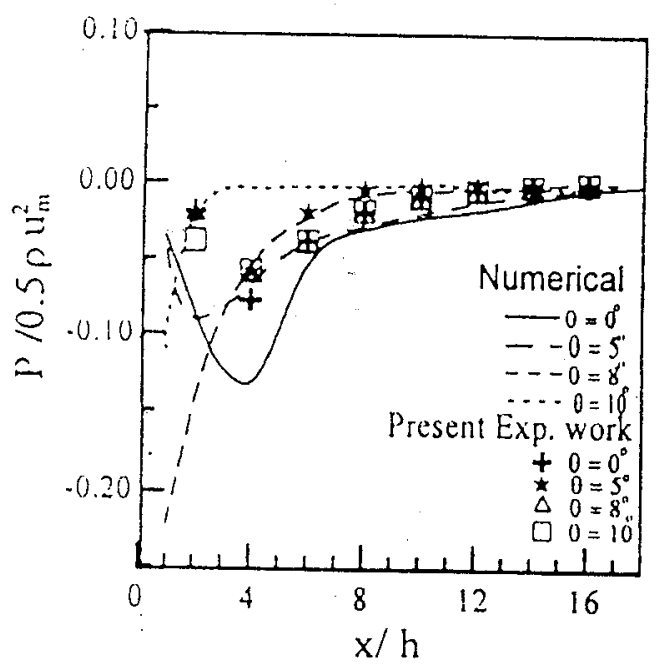

(c) $\mathrm{Re}=86240$

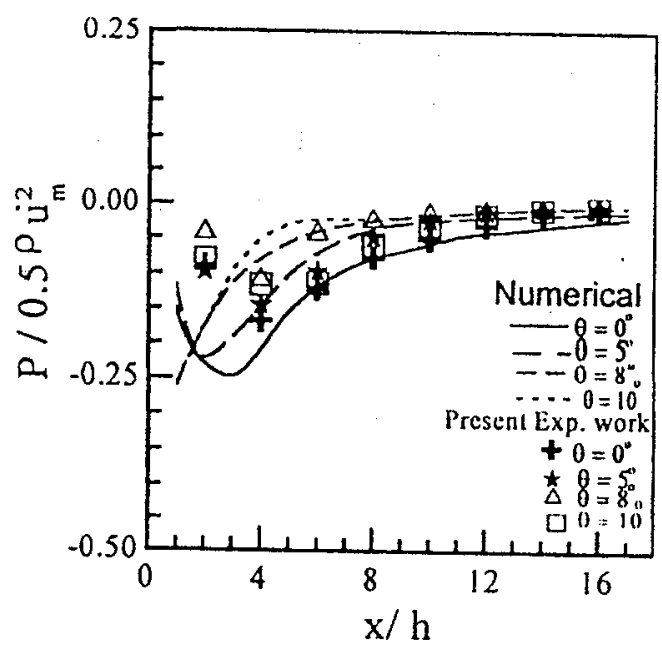

(b) $\mathrm{Re}=56000$

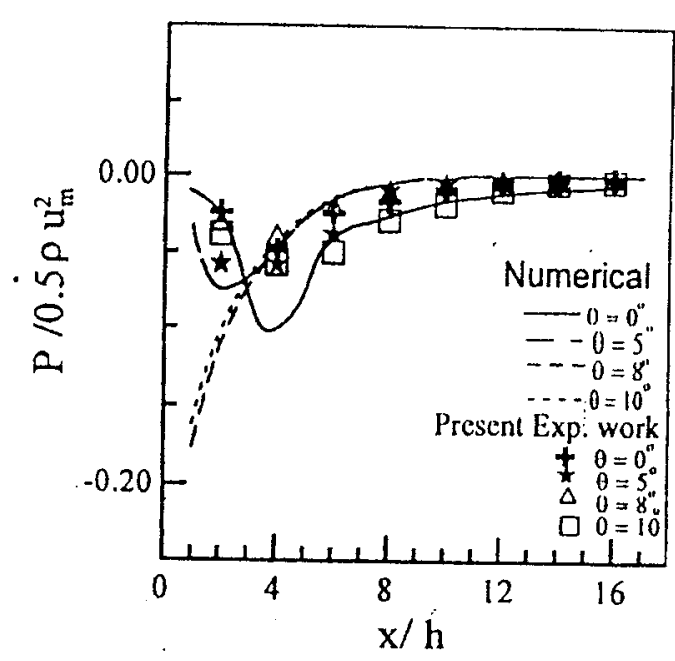

(d) $\operatorname{Re}=108732$

Fig. (15) Wall surface pressure distribution at different wall angle $(\theta)$ 


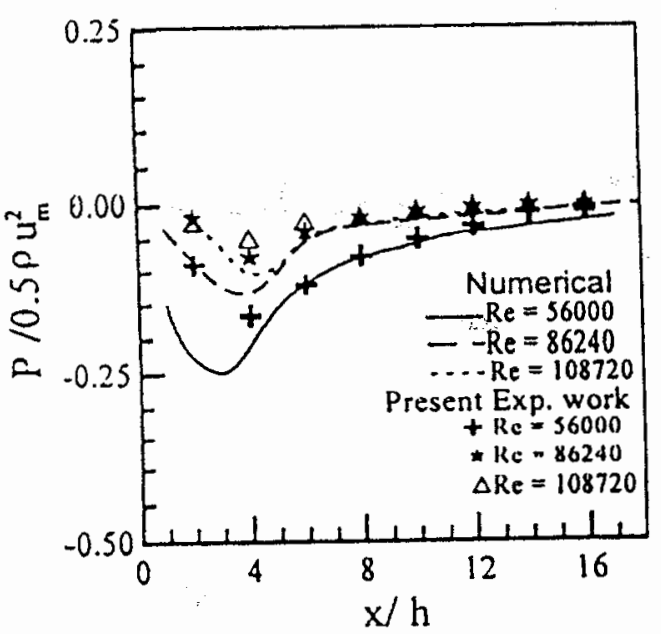

(a) $\theta=0^{\circ}$

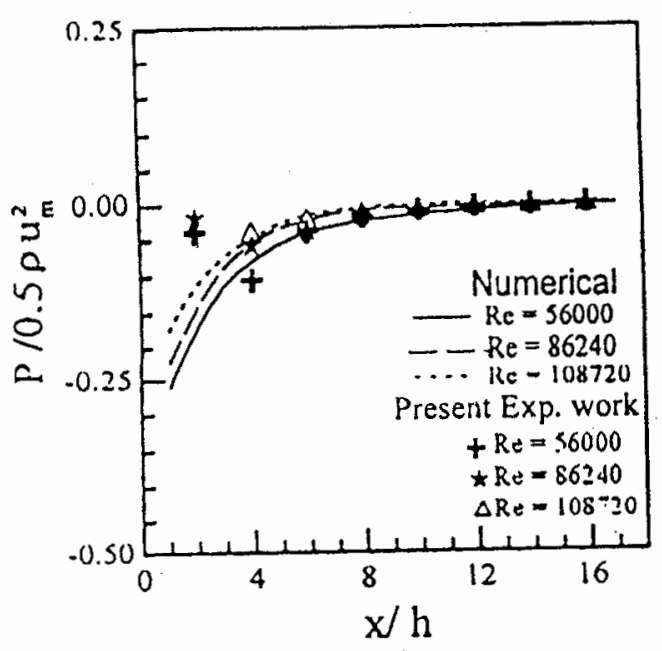

(c) $\theta=8^{\circ}$

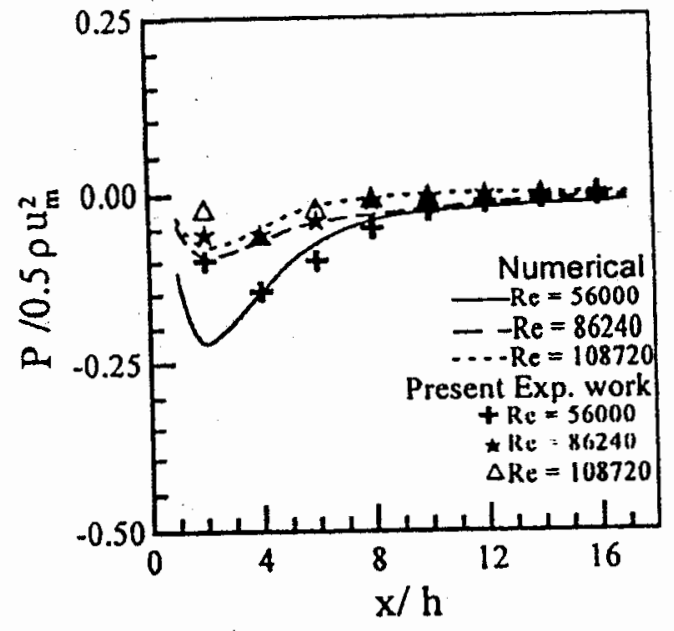

(b) $\theta=5^{\circ}$

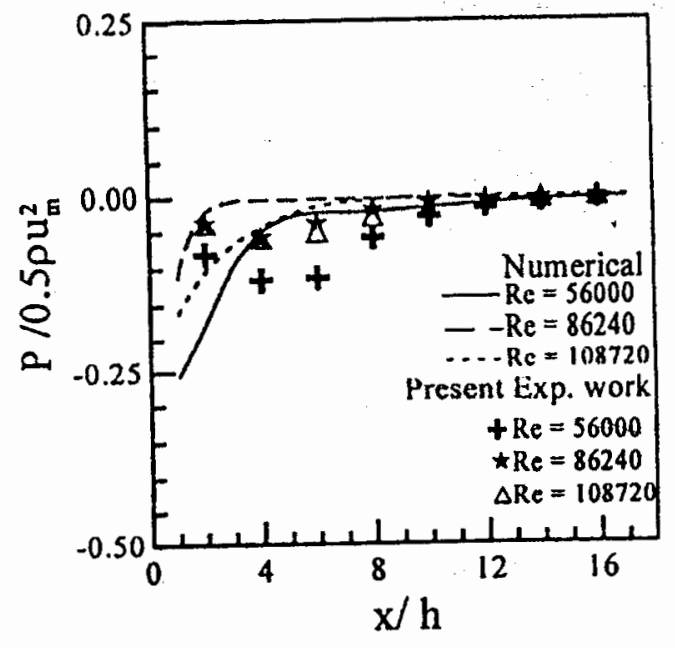

(d) $\theta=10^{\circ}$

Fig. (16) Wall surface pressure distribution at different Re 


\title{
الار اسة النظرية والعملية لتأثير مــيل سـطح النفث الحائطي على خصائص المائع الاضطر ابسي
}

\author{
د. عاشور عبد الفتاح خطاب \\ قسم هندسة الميكانيكية - كلية الهندسة - جامعة المنوفية
}

تعتبر دراسة النفت المنبعث على سطح مسائل ذو أهمية كبــيرة فــي كثـير مسن

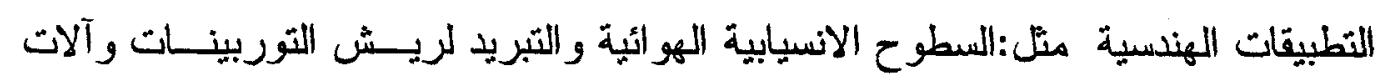

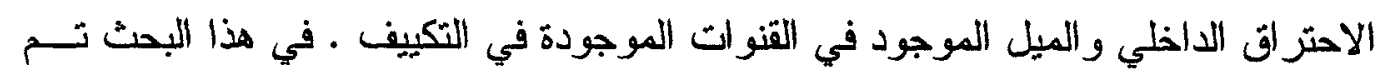

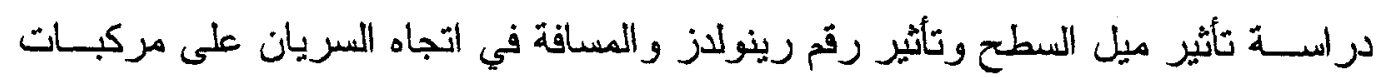

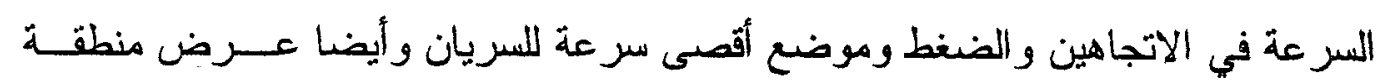

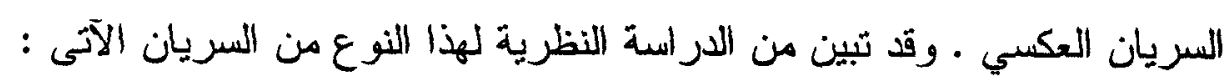

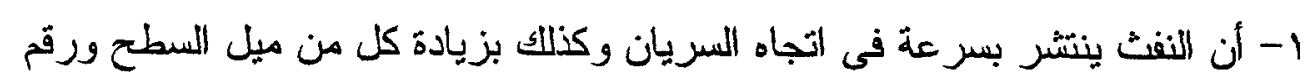

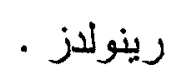

r- أقصى سرعة للسريان تقل بزيادة زاوية السطح وتزيد بزيادة رقم رينولدز • r- نقطة انفصال السريان تتجه نحو اتجاه دخول السريان بزيادة زاوية ميل الحائط

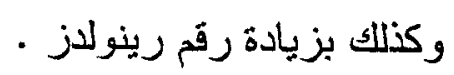

ع- عرض السريان الثانوي الناشئ يزداد بزيادة كل من ميل ميل السطح ورقم رينولاز . 0- الضغط يزداد بزيادة ميل السطح .

وفد تثم عمل مقارنة بين الدراسة النظرية والدراسة العطلية التى نفذت فى هذا

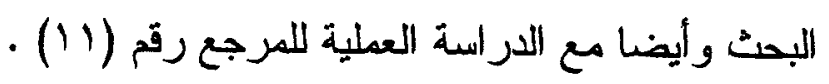

